\title{
Do House Prices Deliver Misleading Information?
}

\author{
Ruihu Kuang \\ Australian School of Business, University of New South Wales, Sydney NSW 2052 Australia \\ r.kuang@student.unsw.edu.au,wrx323@163.com
}

\begin{abstract}
Identifying whether housing prices have misled the market or not at present is an important topic in real estate regulation management in China. Many scholars believe that house prices cannot mislead the market, and try to attribute the rapid rise of house prices to factors such as excessive investments and less municipal governments' regulation, which evidently is not completely convincing. The significance of this paper is to give a new scientific answer to the questions above through rigorous empirical analyses. The methodologies for analyzing the relationships between house prices and determinants were based on a fix effects model and a dynamic model considering cross section dependence, using fix effects regression and the augmented mean group (AMG) estimation. The estimation results demonstrate that the average residential house prices do not response to any change in different variables (determinants), which are average incomes, real estate investments and construction costs except the house bubbles. Thus, house prices deliver misleading information, which proves that the scholars' viewpoint is false. Excessive investments from institutions and less regulation from municipal governments might be misled by the false information reflected in the house prices.
\end{abstract}

Keywords-fix effects regression; augmented mean group (AMG) estimation; house bubble; misleading information; estate market.

\section{PREAMBLE}

It is no exaggeration to say that the regulation of real estate is the top priority of the social management of the present government in China. And rapid property price growth in Chinese cities also causes the attention and discussion of many scholars. Eddie Chi Man Hui et al $(2012)^{[1]}$ found out explosive bubbles periodically affected Guangzhou and Shenzhen. Wu Yanxia et al. $(2006)^{[2]}$ verified the real estate bubbles existing in whole nation, shanghai, and Hainan. Due to inflated house prices, some academics tried to study the determinants of driving high house prices in cities, such as individual demands, institutional investments, land demands, and credit controls, etc. N. Edvard Coulson et al $(2013)^{[3]}$ investigated factors of individual choices in real estate investments. In their findings, residents in most Tier-1 cities invested in less property, and many households chose to invest non-locally. Particularly large migrants tended to return to previous locations. What are the reasons for overpriced houses in Chinese cities if Individual investments are not the reason? Ashvin Ahuja et al(2010) ${ }^{[4]}$ showed that low real interest rates and lack of alternative investment stimulated high property price growth. State-owned enterprises controlled by the central government also were blamed for dramatic growth in house prices in cities. Jing Wu et al. $(2013)^{[5]}$ illustrated that the state-owned enterprises paid $27 \%$ more than other bidders for purchasing an equivalent land parcel. The behaviors of the enterprises were similarly identified by Weidong Qu (2012) ${ }^{[6]}$. However, it is possible that the excessive institutional investments, land demands and limited credit controls may come from misleading information transmission. If house bubbles existed in house prices, there would be significant development in real estate. Institutions could be induced by the fake prosperity of real estate and invest more in the industry. Governments in cities also could be deceived by the abnormal prosperity and pay less attention to regulating real estate industry. Thus, the paper contributes to provide an empirical evidence of whether house prices deliver misleading information.

\section{VARIABLES AND DATA USED IN ANALYSES}

Variables consist of average residential house prices, average incomes, construction costs, real estate investments in Chinese cities in different years. Average residential house prices are measured in yuan per square meter, while average incomes are measured in yuan in a year in cities. Construction costs reflect unit price of a completed house in cities, measured in yuan per square meter. They include land price, labors and materials, etc .Real estate investments denotes amount of real estate investments in cities, measured in 10000 Yuan.

Panel data are based on China Statistical Yearbook. These data, selected in Chinese city levels, are annually from 1996 to 2012 and include 31 provinces.

\section{MeTHOdOLOGIES}

My analyses follow two steps. First, I examine whether there are relationships between average residential house prices and determinants including average incomes, construction costs, and real estate investments. I also further interpret the relationships and test whether the relationships are reliable. In the step, I aim to find out relationships between house prices and the determinants, no matter whether house bubbles are hidden in house prices. In the second step, I attempt to discover relationships between house prices and the determinants when an unobservable variable, considered as house bubbles, is set up to be separated from house prices. By comparing relationships analyses in the first step with 
relationships in the second step, I can identify whether house prices provide misleading information.

In the first step, I use a fix effect model to investigate the relationships. The model is specified as follows.

$$
\log P_{i t}=\alpha_{i}+\beta \times \log M_{i t}+\varepsilon_{i t}
$$

Where $P_{i t}$ is natural log of average residential housing prices in different cities $i$ in different year $t . M_{i t}$ is a set of natural $\log$ of variables including average incomes, construction costs, and real estate investments in different cities $i$ in different years $t$. To control the unobservable time-invariant city effect, $\alpha$ plays an important role. $\varepsilon_{i t}$ denotes the error terms and are assumed to be independently distributed with zero mean and variance $\sigma^{2}$. $\beta$ are coefficients of $M_{i t}$ and reflects relationships between $\log P_{i t}$ and $\log M_{i t}$.

To estimate the model, fix effects regression is used. When the average residential housing prices contain bubbles, the estimation results from the regression must be bias even though the results can pass consistent tests, such as $t$ test or $F$ test. To detect whether the results are bias, I conduct pesaran test (Pesaran, M.H., 2004 ${ }^{[7]}$ ) to test the cross-sectional dependence in fixed effects panel data models. In the panel data models, the standard assumption is that the error terms are independent across crosssections. This assumption is based on the identification purpose. But the cross-sectional independence in panel data models exists, which violates the assumption. Thus, cross-sectional tests are employed to test descriptive accuracy of panel data models. Pesaran test is one of cross-sectional tests. The test is better than other crosssectional tests in two aspects. One is that it is suitable to test panel data models with small $\mathrm{T}$ and large $\mathrm{N}$. The other one is that it can handle balanced as well as unbalanced panels.

In the second step, a dynamic empirical model for analysing house prices which include evolving house bubbles is firstly formalised as below.

$$
\begin{aligned}
& \log P_{i t}=\alpha_{i t}+\beta \times \log M_{i t}+V_{i t} \\
& V_{i t}=c \times K_{t}+\varepsilon_{i t} \\
& K_{t}=\pi \times K_{t-1}+\zeta_{i t}
\end{aligned}
$$

In this setup, cross-section dependence is captured by an unobservable common factors $\mathrm{K}_{\mathrm{t}} \cdot \alpha_{\mathrm{it}}$ is a constant.

The error components of eit and $\zeta$ it are assumed to be independently distributed with zero mean and variance $\sigma^{2}$. $\log P_{i t},, \log M_{i t}$ and $\beta$ have the same definitions as in the former model. The methodology to estimate the model is augmented mean group estimator (AMG), introduced by Eberhardt and Teal (2010) ${ }^{[8]}$. The advantage of the method is that it does not require variables to be stationary and eliminates potential bias for analyzing relationships between non-stationary variables. Besides, the method considers a dynamic unobservable variable into estimation, which represents house bubbles in my case. Some literature, such as Eddie Chi Man Hui, et al. (2013) employs the dynamic unobservable variable as house bubbles as well.

The AMG estimator proceeds in the following two stages.

$$
\begin{aligned}
& \Delta \log P_{i t}=\beta \times \Delta \log M_{i t}+\sum_{2}^{T} C_{t} \times \Delta G_{t}+\varepsilon_{i t} \\
& \log P_{i t}=\alpha_{i t}+\beta \times \log M_{i t}+\hat{C}_{t} \times g_{i}+\varepsilon_{i t}
\end{aligned}
$$

Where, $P_{i}, M_{i}, \alpha_{i t}$ and $\beta$ are the same as in the former model. The term $\sum_{2}^{T} C_{t} \times \Delta G_{t}$ is used to estimate the dynamic house bubbles.

The first stage is implemented by pooled OLS regression of the first-differences model in (5). The estimated coefficients augmented with $\mathrm{T}-1$ differenced year dummies $G_{t}$, labelled as $\hat{C}_{t}$ indicate evolution of an unobservable variable over time. It is referred to as the 'common dynamic process'. In the second stage (6), the 'common dynamic process' is imposed on each group member. gi represents the implicit factor loading of on the common evolving unobservable variable. After subtracting $\hat{C}_{t} \times g_{i}$ from $\log P_{i t}$, long term real relationships between $\log P_{i t}$ and $\log M_{i t}$ can be identified.

TABLE I. THE FIX EFFECTS REgResSION OPERATION AND RESULtS

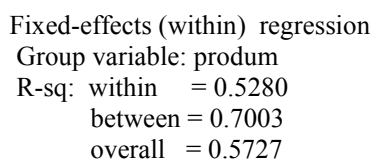

\begin{tabular}{|c|c|c|c|c|c|c|}
\hline logprice & Coef. & Std.Err. & $\mathrm{t}$ & $\mathrm{P}>|t|$ & \multicolumn{2}{|c|}{ [95\% Conf. Interval] } \\
\hline logincome & 0.2632023 & 0.1398282 & 1.88 & 0.060 & -0.0115304 & 0.537935 \\
\hline logresiv & 0.1049992 & 0.0485656 & 2.16 & 0.031 & 0.0095781 & 0.2004202 \\
\hline logcomvalu & 0.4370958 & 0.1191102 & 3.67 & 0.000 & 0.2030696 & 0.671122 \\
\hline cons & 0.5842301 & 0.5598902 & 1.04 & 0.297 & -0.5158353 & 1.684295 \\
\hline
\end{tabular}

F test that all u $\quad \mathrm{i}=0: \quad \mathrm{F}(30,493)=5.64 \quad$ Prob $>\mathrm{F}=0.0000$

Note: logprice, logincome, logresiv and logcomvalu represent natural logs of average residential house prices, average incomes, real estate investments and construction costs respectively. 


\section{EMPIRICAL RESULTS}

\section{A. Results of the fix effects regression}

Before I interpret the coefficients of the model, I explain reliability of the model results based on the consistent test presented in the Table 1 . The table indicates that there is joint significance for all coefficients as $p$ value for $F$ test statistics is 0 . For all coefficients of the variables, they are significant in $10 \%$ confidence level except the constant, which is not my interest as $\mathrm{p}$ values for all coefficients are less than $10 \%$. As the natural logs are put in front of variables, the coefficients can explain how responsive the average residential house prices are to a change in different variables, which are average incomes, real estate investments and construction costs. For example, the coefficient of logincome indicates that when average incomes increase $1 \%$, average residential house prices increase by $0.26 \%$. Therefore, the order of the significant response is construction costs, average incomes and real estate investments. As it is mentioned as before, the analyses only illustrate the relationships between average residential house prices and determinants when house bubbles are hidden in the house prices. To demonstrate the limitation of the model, the result from pesaran test is exhibited as below.

\section{B. Result of pesaran test}

Pesaran's test of cross sectional independence $=5.628$, $\operatorname{Pr}=0.0000$

The result provides the evidence of potential bias in the former model as probability of accepting the null hypothesis that cross sections are independence is 0 .

\section{Results of the AMG estimation}

\section{TABLE II. THE AMG ESTIMATION OPERATION AND RESULTS}

Augmented Mean Group estimator (Bond \& Eberhardt, 2009; Eberhardt \& Teal, 2010)

Common dynamic process included as additional regressor

All coefficients present represent averages across grops (produm)

Coefficient averages computed as unweighted means

Mean Group type estimation $\quad$ Number of obs $\quad=\quad 527$

Group variable: produm $\quad$ Number of groups $=31$

Obs per group: $\min =17$

avg $=17.0$

$\begin{aligned} \max & =17 \\ \text { Wald chi2 (3) } & =7.00\end{aligned}$

Prob $>$ chi2 $=0.0720$

\begin{tabular}{|c|c|c|c|c|c|c|}
\hline logprice & Coef. & Std.Err. & z & $\mathbf{P}>|z|$ & {$[95 \%$ conf } & \\
\hline logincome & 0.114067 & 0.4496696 & 0.25 & 0.800 & -0.7672692 & 0.9954031 \\
\hline logresiv & 0.066939 & 0.0991777 & 0.67 & 0.500 & -0.1274457 & 0.2613237 \\
\hline logcomvalu & 0.1883674 & 0.2002146 & 0.94 & 0.347 & -0.2040461 & 0.5807809 \\
\hline 00000R_c & 0.9343328 & 0.3769118 & 2.48 & 0.013 & 0.1955993 & 1.673066 \\
\hline${ }^{-}$cons & 3.871977 & 2.267628 & 1.71 & 0.088 & -0.5724928 & 8.316446 \\
\hline
\end{tabular}

Note : logprice, logincome,logresiv and logcomvalu have the same meanings in table 1. 00000R c reflects 'common dynamic process'.

The Table 2 shows that there is joint significance for all coefficients in $10 \%$ confidence level as Prob $>$ chi2 in wald test is $7.2 \%$. For all coefficients of the variables, they are insignificant except the constant and a common dynamic process, as $\mathrm{p}$ values for all coefficients are large than $10 \%$. These results demonstrate that house bubbles, which are treated as the common dynamic process, exist in the house prices. However, the results also confirm that when house bubbles are subtracted from the average residential house prices, all significant relationships between average residential house prices and other variables in the fix effects regression do not appear in the model. In other words, the average residential house prices do not response to any change in different variables, which are average incomes, real estate investments and construction costs except the house bubbles. These analyses can prove that the average residential house prices in cities have less flexible or resilient as expected as they contain house bubbles. Thus, individuals, institutions and governments are easily deceived by information reflected from house prices.

\section{CONCLUSIONS}

(1) The analyses of fix effects regression explain how responsive the average residential house prices are to a change in different variables (average incomes, real estate investments and construction costs). The influence of the variables on housing prices from big to small is construction costs, average incomes and real estate investments, when house bubbles are hidden in house prices. These analyses indicate the real estate markets in cities are blind and have their limitations to a considerable extent.

(2) The AMG estimation results indicate that there are no significant relationships between the house prices and determinants (variables) when house bubbles are separated from house prices. In essence, real estate bubbles make housing prices distorted.

Based on the two points above, it illustrates that economic bodies are easily misled in the housing market. Excessive demands, investments from individuals or institutions and less regulation from governments in cities 
might happen, which promote dramatic growth in the house prices.

\section{REFERENCES}

[1] Eddie Chi-Man Hui, Cong Liang, Ziyou Wang et al., Real Estate Bubbles in China: A Tale of Two Cities. Construction Management and Economics, 30, pp.951-961, 2012.

[2] Wu Yanxia et al., Study on Real Estate Bubble Causes and Speculative Measurement, Forecast, 2, pp. 12-17, 2006

[3] N. Edvard Coulson et al., Institutional and Demographic Influences on the Presence, Scale and Geographic Scope of Individual Chinese Real Estate Investment. Regional Science and Urban Economics, 43, pp.187-196, 2013.
[4] Ashvin Ahuja et al., Are House Prices Rising Too Fast in China? Hong Kong Monetary Authority, Working Papar, 2010.

[5] Jing Wu et al., Is There Evidence of a Real Estate Collateral Channel Effect on Listed Firm Investment in China? NBER Working Paper $18762,2013$.

[6] Weidong Qu et al, Assessing the Performance of Chinese Land Lease Auctions: Evidence from Beijing. Journal of real estate research, 34, pp.291-310, 2012.

[7] Pesaran, M.H. , General diagnostic tests for cross section dependence in panels, Cambridge Working Papers in Economics, 0435, University of Cambridge, 2004.

[8] Eberhardt, Markus and Francis Teal, Productivity Analysis in Global Manufacturing Production, Economics, Series Working Papers 515, University of Oxford, Department of Economics, 2010. 